\title{
SUSTAINABILITY AND OUTREACH: A COMPARATIVE STUDY OF MFIs IN SOUTH ASIA AND LATIN AMERICA AND THE CARIBBEAN
}

\author{
Sefa Awaworyi Churchill* and Ana Marr $\dagger$ \\ *Monash University, Melbourne, Australia, and †University of Greenwich, London, UK
}

\begin{abstract}
Previous studies indicate that microfinance institutions (MFIs) in Latin America and the Caribbean (LAC) have different operational strategies to MFIs in South Asia (SA). Given the recent emphasis placed on the feasibility of MFIs to achieve the dual goals of outreach and sustainability concurrently, we examine and compare the relationship between sustainability and outreach of MFIs in LAC with MFIs in SA. Our results indicate that trade-offs exist between outreach and sustainability in both regions. However, the severity of trade-off is dependent on which goal MFIs decide to focus on in each region.
\end{abstract}

Keywords: microfinance, sustainability, outreach, financial performance, South Asia, Latin America

JEL classification numbers: L26, G21

\section{INTRODUCTION}

Microfinance emerged in the 1970 s as a tool to help alleviate the prevailing poverty conditions and provide financial services to individuals and households who were excluded from the traditional financial system. According to a report by the World Bank, the microfinance movement has fundamentally altered the financial landscape in most developing countries while challenging the traditional financial system and government thinking. As a result, in Latin America and South Asia, microfinance provides most of the financial services to low-income individuals and households (World Bank, 2007). Beyond the role of microfinance in promoting the financial sector (see, Inoue and Hamori, 2013), the industry has contributed significantly towards the engagement of women and empowering them towards their social and economic well-being. In countries such as India and Bangladesh, the emergence of self-help groups (SHGs) has led to the promotion of female empowerment programmes, and in a socially conservative country such as Afghanistan, women are accorded explicit recognition as economic agents as a result of microfinance interventions. Notwithstanding, the microfinance system is largely independent of the conventional financial sector and very recently, the sustainability of the industry has raised significant concerns.

Correspondence: Sefa Awaworyi Churchill, Monash University, Wellington Rd, Clayton VIC 3800; Email: sefa.awaworyi@monash.edu 
Several studies present arguments supporting the existence of a trade-off between outreach and sustainability (see, e.g., Hulme and Mosley, 1996; Conning, 1999; Zeller et al., 2003; Olivares-Polanco, 2005; Quayes and Khalily, 2014). Evidence suggests that in an attempt to become sustainable, MFIs end up reaching out to the poor (i.e., relatively well-off clients) rather than the poorest. Navajas et al. (2000) indicate that high transaction costs are catalysts to the trade-off between financial performance and outreach. Thus, given that smaller loans targeted to the poorest are expensive, MFIs rather prefer to issue larger loans which are usually targeted to the less poor in order to become and/or remain financially viable. Evidence presented by Cull et al. (2007) suggests that microfinance service to the poor and sustainability can be achieved concurrently. However, there is evidence of a trade-off when the poorest are served. In contrast, other studies argue that sustainability and outreach depth are complementary objectives and thus there may not necessarily be a trade-off between these goals (see, e.g., Rhyne, 1998; Woller, 2007; Mersland and Strøm, 2010; Quayes, 2015). Arguments presented in these studies suggest that as MFIs serve more clients, transaction costs are reduced and this helps in attaining sustainability since transaction costs are major determinants of financial performance. Relatively few studies provide evidence to support these arguments. For instance, Fernando (2004), Hishigsuren (2007) and Makame (2008) use different samples but all came to the conclusion that there is no significant trade-off between sustainability and outreach.

Considering the emergence of the recent debates concerning the trade-off between microfinance sustainability and outreach, we set out to examine whether the trade-off phenomenon differs between Latin America and the Caribbean (LAC) and South Asia (SA), and what region specific features account for the differences, if any. Latin America and the Caribbean (LAC) and South Asia (SA) are two regions in which the microfinance movement emerged around the same time (i.e., the 1970s) and have since become well-established in microfinance. However, the microfinance industry in both regions has developed some distinct characteristics. For instance, in SA, microfinance is typically rural rather than urban. Microfinance effectively started in SA at a time when poverty was extensively under scrutiny and thus it is not surprising that the industry is well rooted in the poverty discourse.

However, in LAC, microfinance is more focused on designing financial products for microenterprises than on poverty. The industry in LAC also operated more like a business and thus was seen as a branch of the commercial banking system. This difference in operation can potentially be attributed to the economic conditions of both regions at the time microfinance began. Specifically, in the 1970s when microfinance began in Bangladesh, it was driven by a strong sense of idealism to address issues of poverty in rural areas which was widespread in the country as a result of the aftermath of the Bangladesh Liberation War. In contrast, as a result of the collapsing Bolivian populist regime, there was a widespread unemployment which led to the establishment of Banco Sol to help address issues of urban unemployment (Weiss and Montgomery, 2005). Thus, microfinance emerged in LAC as a tool to provide credit to the informal sector in building successful microenterprises in urban areas. This led to the early embrace of the notion of profitability and commercialization in the region. With these initial ideological and economic differences surrounding the start of the industry in both regions, and by composition with LAC, microfinance in SA was more concerned about alleviating poverty than building successful microenterprises. In addition, microfinance in LAC focused on the poor rather than the poorest (Rutherford, 2003). Today, the industry in both regions is still characterized by these major differences, with SA more inclined towards the alleviation of poverty while LAC is more oriented towards the promotion of microenterprises.

Evidence suggests that during the 1970s, apart from cooperatives, the average low-income household in SA had no access to financial services and if not for microfinance interventions, they would still be excluded from the financial system. Countries such as Bangladesh and India 
have observed astonishing high growth rates while other countries in the region had later starts with slower growth but have since been well-established as well. In the 1990s, microfinance in Bangladesh grew to include millions of clients and for the first time, a large proportion of low-income households had access to financial services. In India, based on the developed SHGs, the microfinance industry flourished substantially as well.

Although the microfinance movement in both LAC and SA has evolved significantly, the limits of the industry becomes evident when it comes to increasing outreach and remaining financially viable at the same time. Anecdotal evidence suggests that the overall financial performance of MFIs in both regions is improving as the awareness of sustainability increases. However, there is a potential trade-off between sustainability and outreach. According to the World Bank, for-profit microfinance institutions (MFIs) who are committed to the social goals of outreach perform better in terms of depth of outreach compared to MFIs that depend on subsidies (World Bank, 2007). Thus, it is often argued that donor support and subsidies cannot sustain the microfinance industry (see, e.g., Helms, 2006). Furthermore, with the growing emphasis on sustainability, anecdotal evidence suggests that focussing on sustainability adversely affects the social mission of MFIs, especially depth of outreach. This has led to significant debates however very few empirical studies exist on the issue.

Thus, in this study, we examine if there is a trade-off between sustainability and outreach in LAC and SA. Using generalized method of moments (GMM) regressions techniques, we address the issue of endogeneity which has not been addressed fully in the existing literature. For instance, Cull et al. (2007) did not adequately address issues of endogeneity between sustainability and outreach. Quayes (2012), on the other hand, attempt to address the issue of simultaneity but circumvented issues regarding endogeneity. Our study also examines the relationship between sustainability and outreach breadth, which has not received much attention in the existing literature. Furthermore, in order to address limitations in measuring sustainability and outreach, particularly, depth of outreach, we construct measurement indices. Most studies use average loan size as a measure of outreach depth with the assumption that poorer clients prefer smaller loan sizes. Thus, it is argued that as the MFI's average loan size decreases, it reflects the depth of outreach (i.e., more of the poorest are reached). Using this measure can be misleading in some cases, especially when there is a general improvement in the MFI's clientele and thus clients no longer require small loans. The use of measurement indices adequately addresses concerns regarding reliability of sustainability and outreach measures used in the existing literature as it combines the various indicators proposed as proxies for each variable, thereby capturing various dimensions that a single indicator fails to capture. Furthermore, we demonstrate empirically, if the profit status of MFIs in LAC and SA affect the outreach and financial performance of the industry.

The rest of the study is structured as follows. Section II describes the data and variables used in this study as well as the details of the measurement index construction process. Section III gives an overview of the empirical strategy and model specifications. Section IV presents the empirical results and lastly Section V presents a brief discussion of the results as well as conclusions and some policy implications.

\section{DATA AND VARIABLES}

\section{II.1 Data}

The data used for this study was collected from the MIX Market database (The MIX). The MIX provides data on several MFIs worldwide. This data is publicly available and contains 
information self-reported by MFIs to the MIX. Data from the MIX is often regarded as reliable because the MFI self-reported data is audited by the MIX before it becomes available publicly. Data from the MIX is widely used by microfinance researchers. For instance, Cull et al. (2007), Hartarska and Nadolnyak (2007), Kai (2009), Marr and Awaworyi (2012) and Quayes (2012) all used data from the MIX. A major limitation associated with the use of data from the MIX is that data on some relevant variables are not available for certain time periods. The MIX relies on MFIs to provide them with information in order to compute relevant variables. Thus, where MFIs fail to provide such information, data from the MIX becomes limited for some relevant variables. As a result, we use an unbalanced panel dataset in our study.

The study includes data on MFIs from South Asia (SA) and Latin America and the Caribbean (LAC). For both regions, we include data from 2005 to 2012. We include data on 215 MFIs from six South Asian countries and 332 MFIs from 33 countries in LAC. Table 1 presents a summary statistics of the data.

\section{II.2 Variables}

II.2.1 Dependent variables (Indices). We consider two main variables - outreach and sustainability. Outreach in microfinance is categorized into two parts; depth of outreach and breadth of outreach (Schreiner, 2002). With regards to breadth of outreach, given that the total number of borrowers an MFI has over time gives a good indication of that MFIs outreach, it is widely considered as an appropriate measure of outreach breadth. In contrast, depth of outreach is often associated with the 'quality' of a MFI's outreach. Thus, outreach depth concerns the measure of the poorest in society that MFIs have served. Measuring this variable appears to be quite complicated (Quayes, 2012). In order to measure depth of outreach accurately, information on the poverty levels, assets and income levels of clients amongst other things needs to be obtained. Given the unavailability of such data for each MFI client, the commonly used measure of outreach depth in the existing literature is the MFI's average loan size. Microfinance researchers (see, e.g., Cull et al., 2007; Quayes, 2012) have argued that there is a positive correlation between the income level of borrowers and the size of loans they require. Thus, it is expected that poorer clients would opt for smaller loans while the relatively richer clients would opt for larger loans. Others have also argued that the number of female borrowers is an appropriate proxy for outreach depth since the most vulnerable in society are usually women (Bhatt and Shui-Yan, 2001). Thus, MFIs that focus on women are improving their quality of outreach.

In this study, we construct a measurement index for both depth and breadth of outreach. We use average loan size and percentage of female borrowers as indicators for depth of outreach. For breadth of outreach, we use the total number of active borrowers and the MFI's number of offices as measures. Number of offices includes the number of branches as well as administrative sites and other staffed points (e.g., partner local shops), and is highly correlated with the number of borrowers. The emergence of branchless banking which includes the use of mobile banking could prevent MFIs from opening more branches but use technology to increase their breadth of outreach. However, given the level of illiteracy in certain rural areas, the use of technology for banking is likely to deter some borrowers. Thus, in the absence of offices outreach breath could be hindered. This suggests that MFIs with more branches have the advantage of attracting more clients since they make microfinance services more accessible to the poor, especially illiterates. In our regressions, we use these individual indicators as well as the constructed measurement indices.

In constructing the measurement indices, first, we rescale all indicators such that all the reported values range between zero and one. This is done after dealing with all potential 
TABLE 1

Summary statistics

\begin{tabular}{|c|c|c|c|}
\hline Variable Name & Variable Description & $S A$ & $L A C$ \\
\hline Sustainability Index & Index for Sustainability & $\begin{array}{c}0.6476 \\
(0.2653)\end{array}$ & $\begin{array}{c}0.6546 \\
(0.1630)\end{array}$ \\
\hline Outreach Depth Index & Index for Outreach Depth & $\begin{array}{l}0.7326 \\
(0.1496)\end{array}$ & $\begin{array}{c}0.4415 \\
(0.1909)\end{array}$ \\
\hline Outreach Breadth Index & Index for Outreach Breadth & $\begin{array}{c}0.4402 \\
(0.1158)\end{array}$ & $\begin{array}{c}0.5053 \\
(0.3131)\end{array}$ \\
\hline Log of OSS & $\begin{array}{l}\text { Financial Revenue / (Financial } \\
\text { Expense + Impairment Loss }+ \\
\text { Operating Expense) }\end{array}$ & $\begin{array}{c}4.6742 \\
(0.2824)\end{array}$ & $\begin{array}{c}4.7034 \\
(0.2352)\end{array}$ \\
\hline Log of ROA & $\begin{array}{l}\text { (Net Operating Income, less } \\
\text { Taxes)/ Assets, average }\end{array}$ & $\begin{array}{c}0.6149 \\
(1.1549)\end{array}$ & $\begin{array}{c}1.0420 \\
(1.1322)\end{array}$ \\
\hline Log of Profit Margin & $\begin{array}{l}\text { Net Operating Income/ Financial } \\
\text { Revenue }\end{array}$ & $\begin{array}{l}2.4566 \\
(1.0484)\end{array}$ & $\begin{array}{l}2.4306 \\
(0.9898)\end{array}$ \\
\hline $\begin{array}{l}\text { Percentage of Female } \\
\text { Clients }\end{array}$ & $\begin{array}{l}\text { Percentage of borrowers who are } \\
\text { women }\end{array}$ & $\begin{array}{c}85.4462 \\
(25.0022)\end{array}$ & $\begin{array}{r}63.9549 \\
(19.7303)\end{array}$ \\
\hline Log of ALS & $\begin{array}{l}\text { Loan Portfolio, Gross / Number } \\
\text { of Active Borrowers }\end{array}$ & $\begin{array}{l}4.9941 \\
(0.6235)\end{array}$ & $\begin{array}{c}6.5862 \\
(0.8915)\end{array}$ \\
\hline Log of Total Borrowers & Number of borrowers an MFI has & $\begin{array}{l}10.6086 \\
(1.8407)\end{array}$ & $\begin{array}{l}9.2669 \\
(1.5314)\end{array}$ \\
\hline $\begin{array}{l}\text { Log of Number of } \\
\text { Offices }\end{array}$ & $\begin{array}{l}\text { Number of staffed points of } \\
\text { service and administrative sites }\end{array}$ & $\begin{array}{c}3.6648 \\
(1.5584)\end{array}$ & $\begin{array}{c}2.2133 \\
(1.2308)\end{array}$ \\
\hline Log of Loan Loss Rate & $\begin{array}{l}\text { (Write-offs - Value of Loans } \\
\text { Recovered)/ Loan Portfolio, } \\
\text { gross, average }\end{array}$ & $\begin{array}{c}-0.4599 \\
(1.6870)\end{array}$ & $\begin{array}{c}0.2484 \\
(1.4292)\end{array}$ \\
\hline Log of Loan Portfolio & $\begin{array}{l}\text { All outstanding loans issued to } \\
\text { borrowers }\end{array}$ & $\begin{array}{l}15.6115 \\
(1.7947)\end{array}$ & $\begin{array}{l}15.8534 \\
(1.8137)\end{array}$ \\
\hline Cost per borrower & $\begin{array}{l}\text { Operating Expense/ Number of } \\
\text { Active Borrowers }\end{array}$ & $\begin{array}{l}28.0153 \\
(42.0444)\end{array}$ & $\begin{array}{l}197.6583 \\
145.933\end{array}$ \\
\hline Yield & $\begin{array}{l}\text { (Yield on Gross Portfolio } \\
\text { (nominal) - Inflation Rate)/ (1 } \\
\text { + Inflation Rate) }\end{array}$ & $\begin{array}{l}13.5964 \\
(8.0177)\end{array}$ & $\begin{array}{l}30.6246 \\
(20.0556)\end{array}$ \\
\hline $\begin{array}{l}\text { Number of Deposit } \\
\text { Accounts }\end{array}$ & $\begin{array}{l}\text { Number of any type of deposit } \\
\text { account held by an MFI }\end{array}$ & $\begin{array}{c}26.3731 \\
(37.8793)\end{array}$ & $\begin{array}{c}4.0112 \\
(20.2183)\end{array}$ \\
\hline $\begin{array}{l}\text { Mature MFI (dummy } \\
\text { variable, Mature MFI } \\
\text { is } 1 \text { ) }\end{array}$ & & $\begin{array}{c}0.6893 \\
(0.4630)\end{array}$ & $\begin{array}{c}0.8052 \\
(0.3961)\end{array}$ \\
\hline $\begin{array}{l}\text { New MFI (dummy } \\
\text { variable, New MFI is } \\
\text { 1) }\end{array}$ & & $\begin{array}{c}0.1188 \\
(0.3237)\end{array}$ & $\begin{array}{c}0.0607 \\
(0.2388)\end{array}$ \\
\hline $\begin{array}{l}\text { Not-for-profit MFIs } \\
\text { (dummy variable } \\
\text { not-for-profit is 1) }\end{array}$ & & $\begin{array}{c}0.5817 \\
(0.4935)\end{array}$ & $\begin{array}{c}0.6684 \\
(0.4709)\end{array}$ \\
\hline
\end{tabular}

*Mean and Standard Deviation (in brackets) of sample, based on data from MIX Market. 
outlier problems. Depending on which indicator is being rescaled, the rescaling process is done differently. For instance, the variables number of offices, the total number of active borrowers and percentage of female borrowers reflect high outreach only if the recorded values for these variables are increasing. On the other hand, for average loan size, which is expected to reflect the quality of outreach, as the reported values get smaller, it gives an indication of good outreach and vice versa. As a result, in dealing with the former set of variables, we assign the minimum value of zero to the smallest reported value for each variable and a maximum value of one to the largest reported value. All other reported values are rescaled to fall between zero and one. Equation 1 is used for the rescaling of these set of variables. For the latter, we do the opposite using equation 2. Thus, the smallest value is assigned one and the biggest value zero. We then take the arithmetic mean of the pair of indicators that fall under each outreach category.

$$
\begin{gathered}
f(x)_{t}=\frac{(\omega-\alpha)\left(x_{t}-\mathrm{A}_{t}\right)}{\Omega_{t}-\mathrm{A}_{t}}+\alpha \\
f(x)_{t}=\left[\frac{(\omega-\alpha)\left(\mathrm{A}_{t}-x_{t}\right)}{\Omega_{t}-\mathrm{A}_{t}}\right]+\alpha
\end{gathered}
$$

Where $f(x)$ is the computed re-scaled value, $\alpha$ and $\omega$ represent the minimum and maximum values of the new scale respectively (in our case zero and one). A and $\Omega$ represent the minimum and maximum original values of the indicators reported in the sample respectively. With regards to sustainability, indicators are chosen to reflect an MFI's ability to cover its operating costs using internally generated funds or revenue. Thus, indicators of sustainability are usually associated with measures of financial performance which can lead to the permanency of MFIs and their operations. With this understanding, in the existing literature, operational self-sufficiency (OSS), return on assets (ROA) and profit margin are often used as indicators of sustainability. We use each indicator individually as a measure of sustainability in our regressions and a sustainability measurement index constructed from all three indicators. The outreach index construction process explained above is used here as well and given that for all three sustainability indicators observed increases in values reflect good performance, we use equation 1 in the rescaling process.

Lastly, while the indicators included in each of our measurement indices are justified theoretically, we also perform a factor analysis to determine if these indices are valid empirically. From the factor analysis, we note that the highest variance between the indicators in our index is from the depth of outreach index analysis. Results indicate a variance of 0.25 for the percentage of female clients. Thus, for all the variables we include in each constructed index, a very low variance is not accounted for by the other variables, indicating that each variable in our measurement indices are relevant. In addition, the dimensionality of our factors is also well defined given that results indicate factor loadings higher than 85 percent in all cases.

II.2.2 Control variables. The control variables used in this study are consistent with the existing literature. Specifically, we control cost per borrower, number of deposit accounts held by MFIs, MFI age and profit status, as well as loan loss rate and gross loan portfolio. Cost per borrower is considered as an efficiency indicator in the microfinance literature and computed as the ratio of a MFI's operating expense to the total number of active borrowers. A high cost per borrower ratio suggests that MFIs are facing very high operational costs as such it is expected that sustainability would be impacted negatively should this ratio increase. Similarly, if loans become expensive as a result of high cost per borrower, MFIs may resort to the issuance of bigger loans, which in principle, suggests that depth of outreach is impacted negatively. 
The number of deposit accounts held by MFIs is considered as a proxy for the savings level of clients. Higher levels of savings accounts are often considered as leverage for financial institutions, even for economic development. As such, we expect a positive association between deposit accounts and both sustainability and outreach.

Our age variable is a dummy for MFI age. Data from the MIX groups MFIs into three categories of age - new, young and mature. Based on this classification, we introduce dummies for mature and new MFIs in our model, leaving out young as the omitted category. We expect that older MFIs would have the advantage over younger ones in terms of both sustainability and outreach. For profit status, we include a dummy for not-for-profit MFIs in order to capture the effects of MFI profit status on their sustainability and outreach performance. Based on conventional understanding, we expect that not-for-profit MFIs compared to for-profit MFIs would perform better in terms of outreach however when it comes to sustainability, we expect the reverse.

Lastly, an increase in gross loan portfolio is often associated with higher outreach, especially outreach breadth. Also, as the level of loan default increase, the general expectation is that financial performance would be affected negatively. Thus, we expect loan loss rate to have a negative association with sustainability.

\section{EMPIRICAL METHODS AND MODEL SPECIFICATION}

Although we compare four estimation methods, pooled OLS (POLS), fixed and random effects, and the system GMM estimates, our main estimation technique is the system GMM. The system GMM estimator is particularly useful in exploiting the bulk of the variations in our data to improve the precision of estimates. In addition, endogeneity and reverse causality issues have been addressed widely using the system GMM estimator. The system GMM estimator is thus useful in our case given the potential reverse causality between sustainability and outreach. The GMM Model may be stated as follows:

$$
\begin{gathered}
S U S_{i t}=\beta_{1} S U S_{i, t-1}+\beta_{2}^{\prime} \boldsymbol{Z}_{i t}+\vartheta_{i}+\boldsymbol{\mu}_{t}+\varepsilon_{i t} \\
O U T_{i t}=\beta_{1} O U T_{i, t-1}+\beta_{2}^{\prime} \boldsymbol{P}_{i t}+\vartheta_{i}+\boldsymbol{\mu}_{t}+\varepsilon_{i t}
\end{gathered}
$$

where $S U S_{i t}$ and $O U T_{i t}$ are sustainability and outreach, respectively. We use the developed measurement indices as well as the individual indicators involved in the index creation to capture sustainability and outreach. $S U S_{i, t-1}$ is the lagged dependent variable in the sustainability model and $O U T_{i, t-1}$ is the lagged dependent variable in the outreach model. $\vartheta_{i}$ is the unobserved fixedeffect term, $\boldsymbol{\mu}_{t}$ includes time effects, and $\varepsilon_{i t}$ is the residual term in each model.

$\boldsymbol{Z}_{i t}$ and $\boldsymbol{P}_{i t}$ represent a vector of control variables in the sustainability and outreach regressions, respectively. In the sustainability regression, the control variables, $\boldsymbol{Z}_{i t}$, besides our main explanatory variable (i.e., outreach) includes loan loss rate (LLR), cost per borrower (CPB), number of deposit accounts held (DEP), MFI age and profit status. In the outreach regressions, besides our main explanatory variable (i.e., sustainability), the control variables include cost per borrower (CPB), number of deposit accounts (DEP), gross loan portfolio (LP), as well as MFI age and profit status.

Rewriting equations (3) and (4) as difference equations yields;

$$
\begin{gathered}
S U S_{i t}-S U S_{i t-1}=\beta_{1}\left(S U S_{i t-1}-S U S_{i t}-2\right)+\beta_{2}{ }^{\prime}\left(\boldsymbol{Z}_{i t}-\boldsymbol{Z}_{i t-1}\right)+\left(\varepsilon_{i t}-\varepsilon_{i t-1}\right) \\
O U T_{i, t}-O U T_{i, t-1}=\beta_{1}\left(O U T_{i, t-1}-O U T_{i, t-2}\right)+\beta_{2}^{\prime}\left(\boldsymbol{P}_{i t-1}-\boldsymbol{P}_{i t-1}\right)+\left(\varepsilon_{i t}-\varepsilon_{i t-1}\right)
\end{gathered}
$$


Differencing yields unbiased estimates. Specifically, differencing eliminates unobserved coun$\operatorname{try}\left(\vartheta_{i}\right)$ and time $\left(\boldsymbol{\mu}_{t}\right)$ fixed effects, which are possible sources of omitted variable bias. Following Arellano and Bond (1991), the regressors' lagged levels are used as instruments to rectify the potential endogeneity bias, and the correlation between dependent variables and error terms. This is conventionally referred to as the first difference GMM (GMM-DIF) estimation, which assumes weak exogeneity of regressors and the non-correlation of error terms. Building on this, Blundell and Bond (1998) show that the first difference GMM estimator may lead to biased estimates given the presence of weak instruments derived from lagged variables when explanatory variables are persistent. Thus, Blundell and Bond (1998) demonstrates the efficiency of the system GMM (GMM-SYS) estimator over the GMM-DIF estimator. Typically, GMM-SYS estimators generate instruments that remain good predictors for endogenous variables, and thus perform better than the GMM-DIF estimator when series are persistent (Blundell and Bond, 1998).

We ran regressions in STATA using the two-step estimator consistent with Roodman (2006). For the GMM estimator to be consistent, it must pass the Hansen J-test of over-identifying restriction and should have no second-order serial correlation in the error term of the difference. In GMM-SYS estimations, the over-identifying restriction tests examine the joint validity of all instruments, and thus work with the null hypothesis that the over-identifying restrictions are valid. The second-order autocorrelation test examines the null hypothesis that there is no autocorrelation or that the error term is not serially correlated. To check the validity of the models, we conducted these required tests. The results are reported at the bottom of each Table of results. Specifically, given the p-values which are greater than 0.05 , we cannot reject the null hypothesis that the full set of orthogonality conditions are valid. Similarly, given the p-values for the autocorrelation test, we cannot reject the null hypothesis of no second-order serial correlation in the first-differenced error terms.

\section{EMPIRICAL RESULTS}

To start with, we compare four estimations methods that have frequently been used in the existing literature: pooled OLS (POLS), fixed and random effects, and the system GMM techniques. Results for these regressions are reported in Tables 2 and 3, and we combine the data for both regions in one regression while we include a dummy to control for South Asia. Table 2 report regressions on the association between sustainability and depth of outreach, while Table 3 reports on sustainability and breadth of outreach. ${ }^{1}$ In both tables, Panels 1, 2, 3, and 4, respectively, report results for POLS, fixed effect, random effect, and system GMM.

From Table 2, results suggest a trade-off between sustainability and outreach depth. This is consistent across all estimation techniques, except for the random effect regression where the effect of sustainability on outreach is statistically insignificant. Drawing on results from our preferred estimation technique (i.e., the system GMM), a 1 percent increase in outreach depth leads to a 0.09 percent decline in sustainability. Similarly, a 1 percent increase in sustainability leads to a 0.07 percent decline in outreach depth. The regional dummies for South Asia are also significant suggesting that there are significant variations in the observed results for both regions. $^{2}$

Table 3 provides evidence which supports the complementarity between sustainability and breadth of outreach. Specifically, GMM results show that a 1 percent increase outreach breadth

\footnotetext{
${ }^{1}$ Indices of sustainability and outreach are used in these regressions.

${ }^{2} \mathrm{We}$ explore these variations in details in the next sub-section.
} 


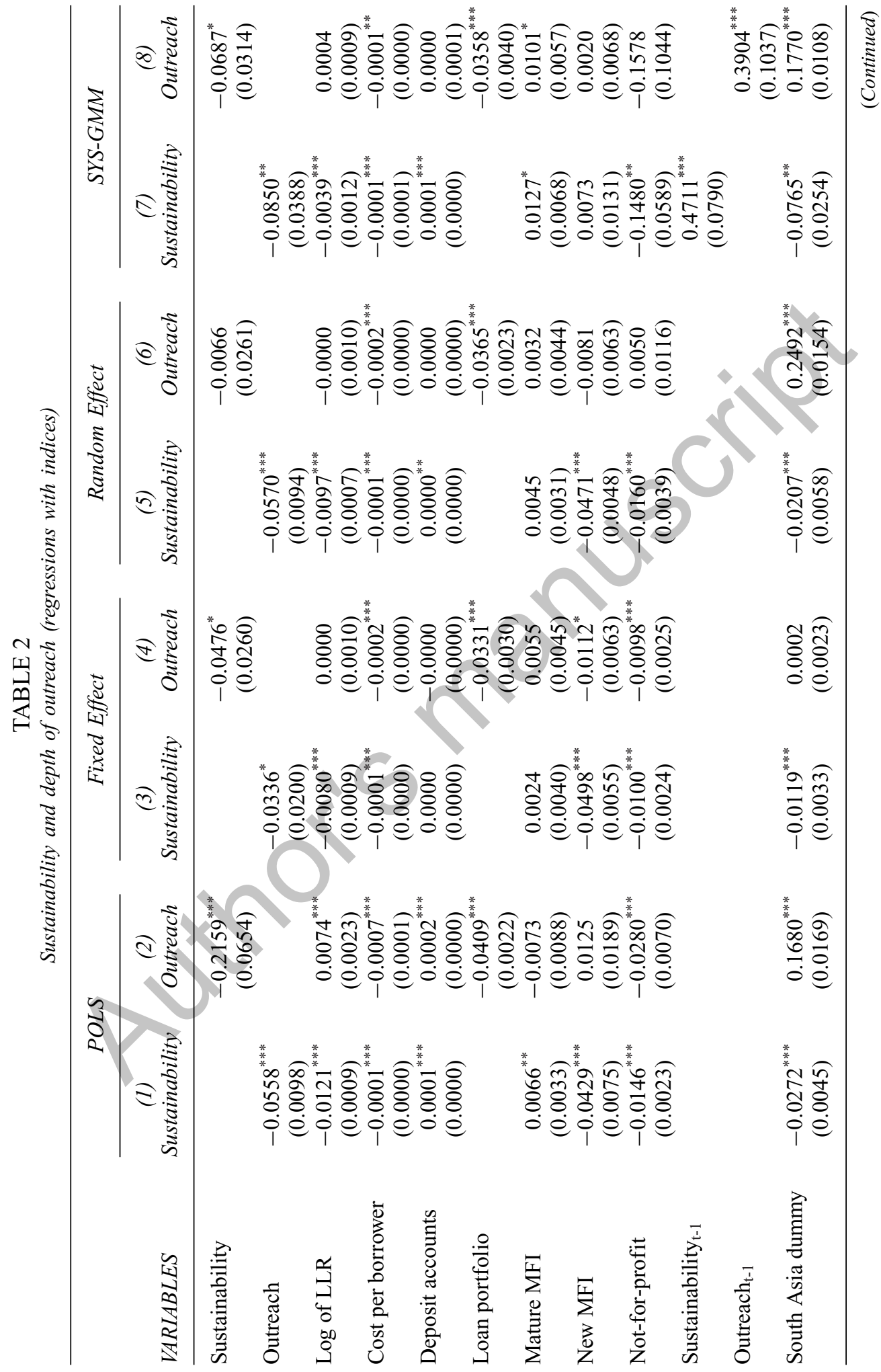


Bulletin of Economic Research

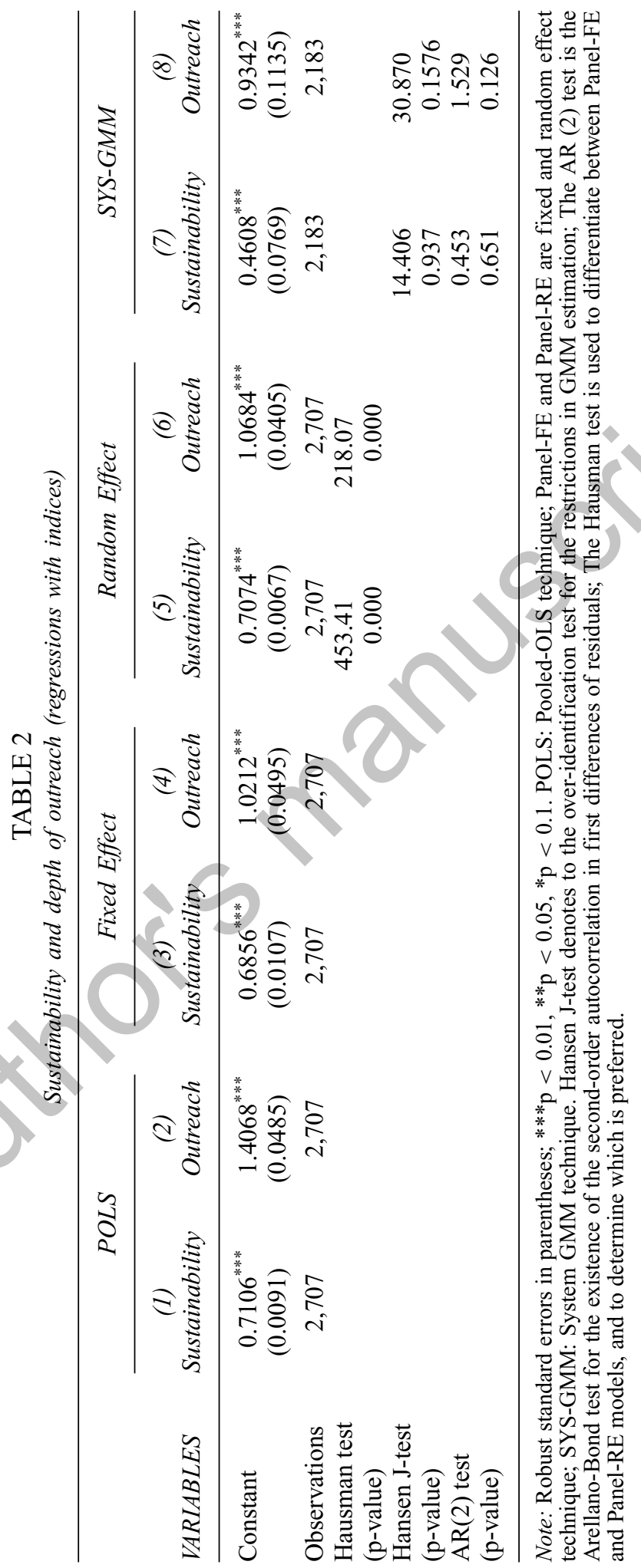




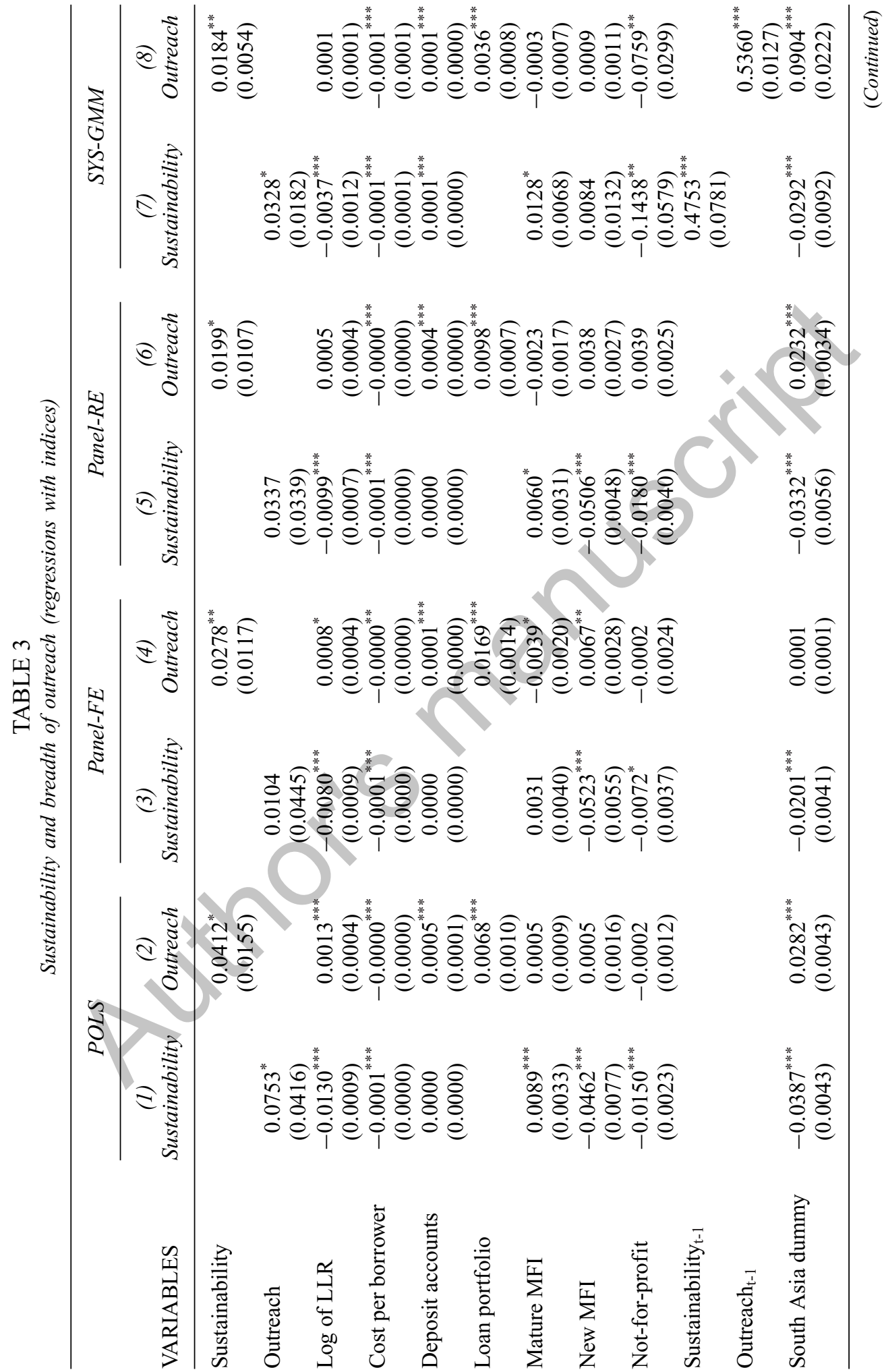


Bulletin of Economic Research

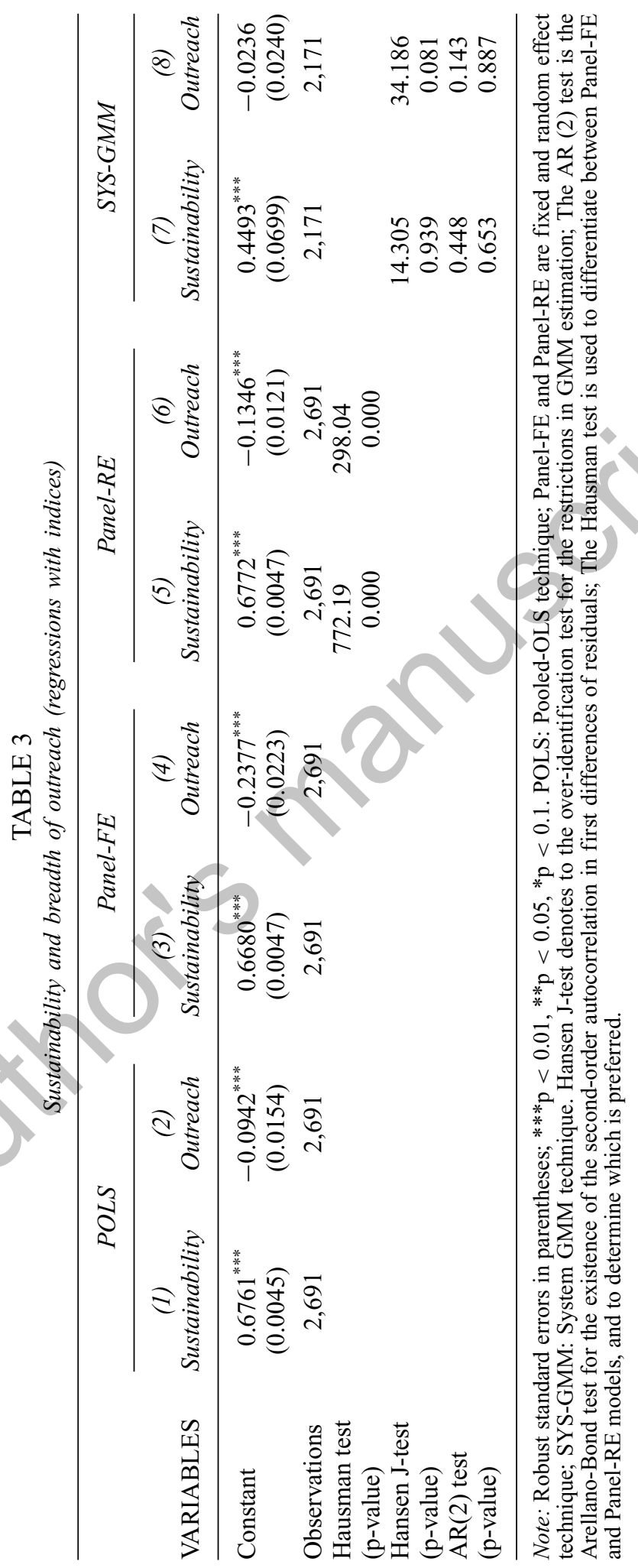


leads to a 0.03 percent increase in sustainability, while a 1 percent increase in sustainability leads to a 0.02 percent increase in outreach. POLS results also show a similar relationship. However, for the fixed and random effect models, while sustainability has a positive effect on outreach breadth, the effect of outreach breadth on sustainability is statistically insignificant.

\section{IV.1 Latin America and the Caribbean Vs South Asia}

IV.1.1 Effects using sustainability and outreach indices. Table 4 presents results that compare LAC and SA. Panel 1 presents results for LAC while Panel 2 for SA. Odd columns present results for sustainability regressions while even columns present results for outreach. ${ }^{3}$ From Panel 1, we observe that at the 1 percent significant level, for LAC, a percentage increase in depth of outreach leads to a 0.09 percent decline in the level of sustainability while a percentage increase in sustainability leads to a 0.52 percent decline in outreach depth. This suggests that there is a trade-off between sustainability and depth of outreach in LAC. Similarly, we observe that for SA, a 1 percent increase in depth of outreach leads to a 0.12 percent decline in the level of sustainability while a 1 percent increase in sustainability is associated with a 0.41 percent decline in the level of outreach depth. Thus, results indicate a trade-off between sustainability and depth of outreach in both regions. However, we find that MFIs in LAC that focus on increasing performance in terms of outreach depth perform better with sustainability than MFIs that do same in SA. This is evident considering the stronger negative coefficients of outreach depth on sustainability for SA. In contrast, we find that for MFIs in LAC, the decline in outreach depth when MFIs focus on sustainability is greater than what is observed for MFIs in SA. Thus, while there is a trade-off between sustainability and depth of outreach in both regions, the severity of trade-off is dependent on which performance indicators MFIs decide to focus on in each region.

We now turn to the results for the association between sustainability and breadth of outreach. Results from Table 4 Panel 1 suggest that, in LAC, there is outreach breadth has no statistically significant effect on sustainability. However, a 1 percent increase in sustainability leads to a 0.02 percent increase in breadth of outreach. In SA, for a 1 percent increase in sustainability, there is a corresponding 0.19 percent decline in breadth of outreach. Further, a 1 percent increase in outreach breadth, leads to a 0.20 percent decline in sustainability in SA. This points to a trade-off between sustainability and breadth of outreach in SA but not in LAC.

IV.1.2 Sustainability and depth of outreach indicators. Table 5 presents results for the association between sustainability and depth of outreach using individual indicators included in our indices. Panel 1, 2 and 3, respectively, present results for the effects of ROA, profit margin and OSS on depth of outreach indicators. From Panel 1, we observe that for SA, if the percentage of female clients increases by 1 percent, there is a corresponding 0.09 percent increase in ROA. However, a 1 percent increase in ROA leads to a 1.96 percent increase in the percentage of female clients. On the contrary, evidence suggests that there is a trade-off between ROA and percentage of female clients in LAC. Similar associations are observed in Panels 2 and 3 as well, where results indicate that there is a trade-off between profit margin and percentage of female clients in LAC but not in SA. An exception is the case of Panel 3, where results for SA are statistically insignificant.

From Table 5, we observe that in the case SA, there is no significant effect of ROA on average loan size. However, an increase in ALS is associated with a 0.6 percent increase in ROA. For LAC, there is evidence of a trade-off. A 1 percent decrease in depth of outreach (i.e., increase in

\footnotetext{
${ }^{3}$ Results here are based on the constructed indices for sustainability and outreach. In the next section, we also examine the relationship using the individual indicators included in our indices.
} 


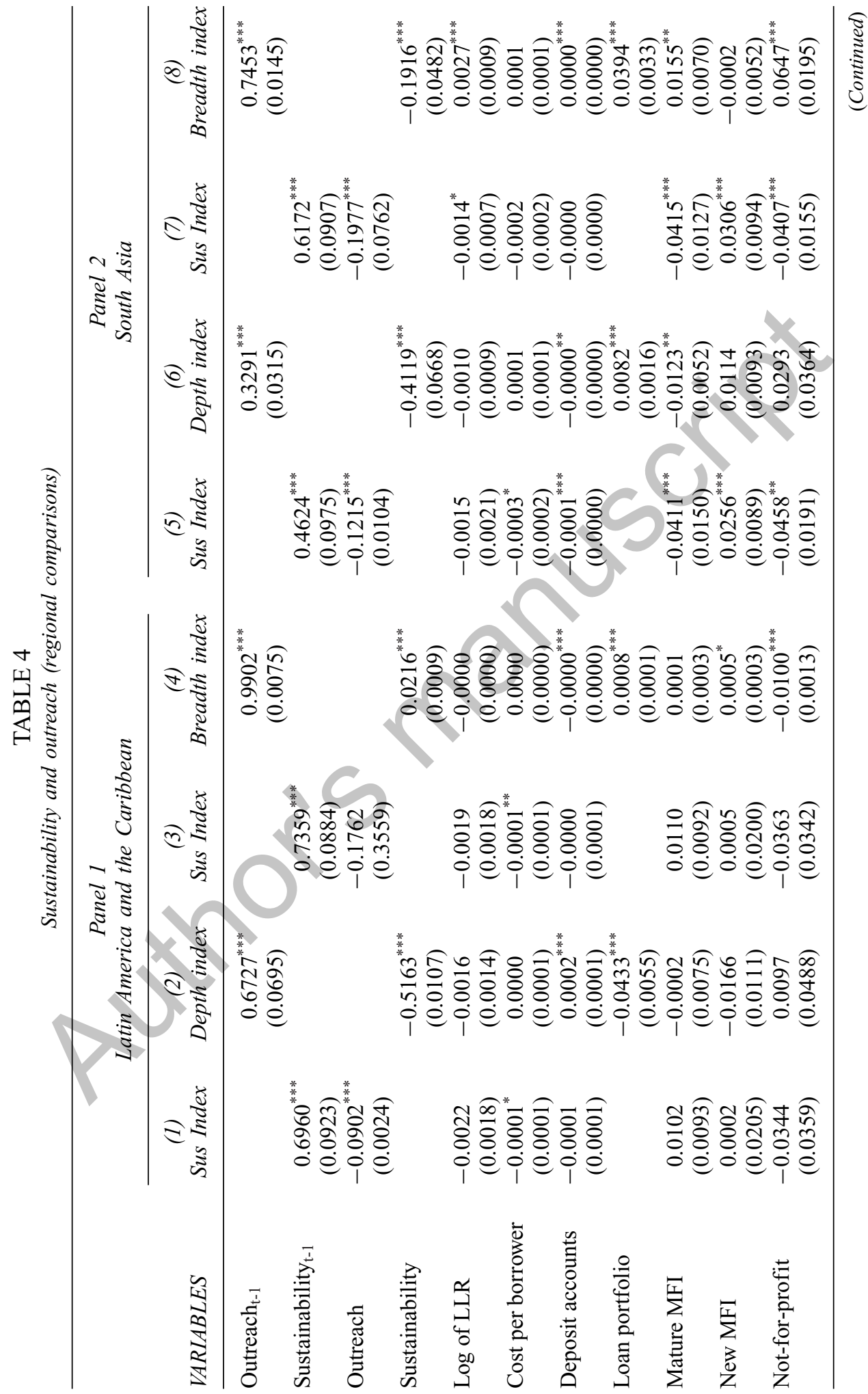




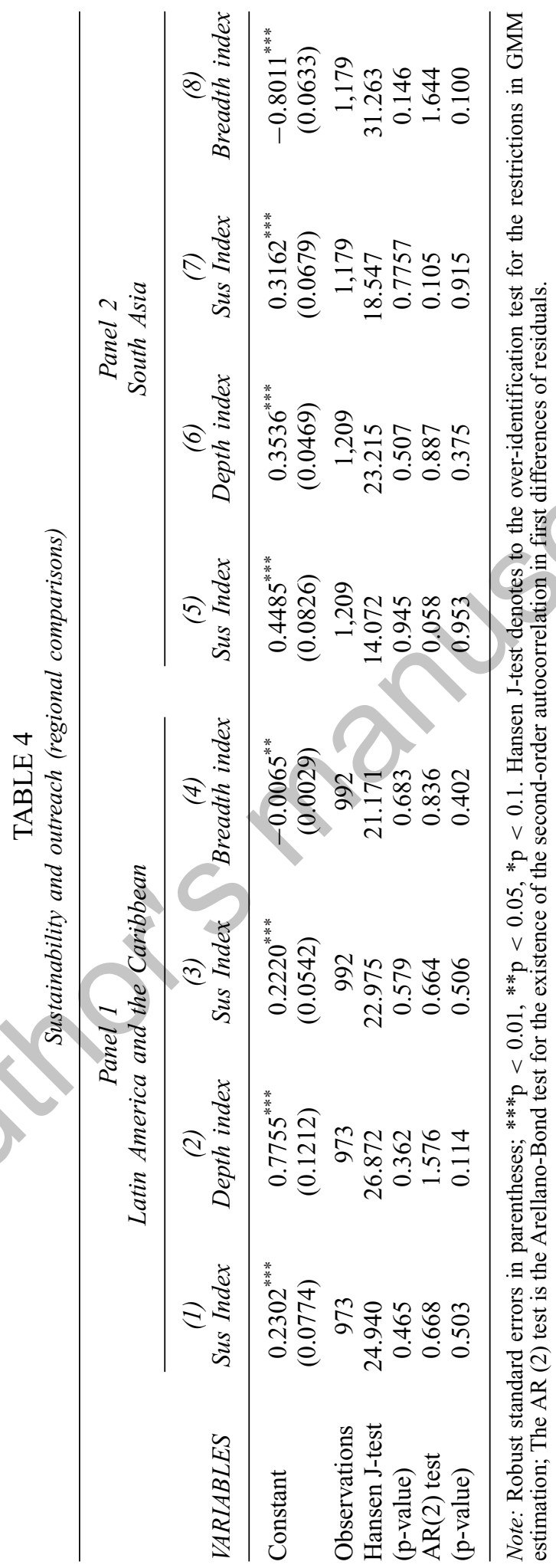




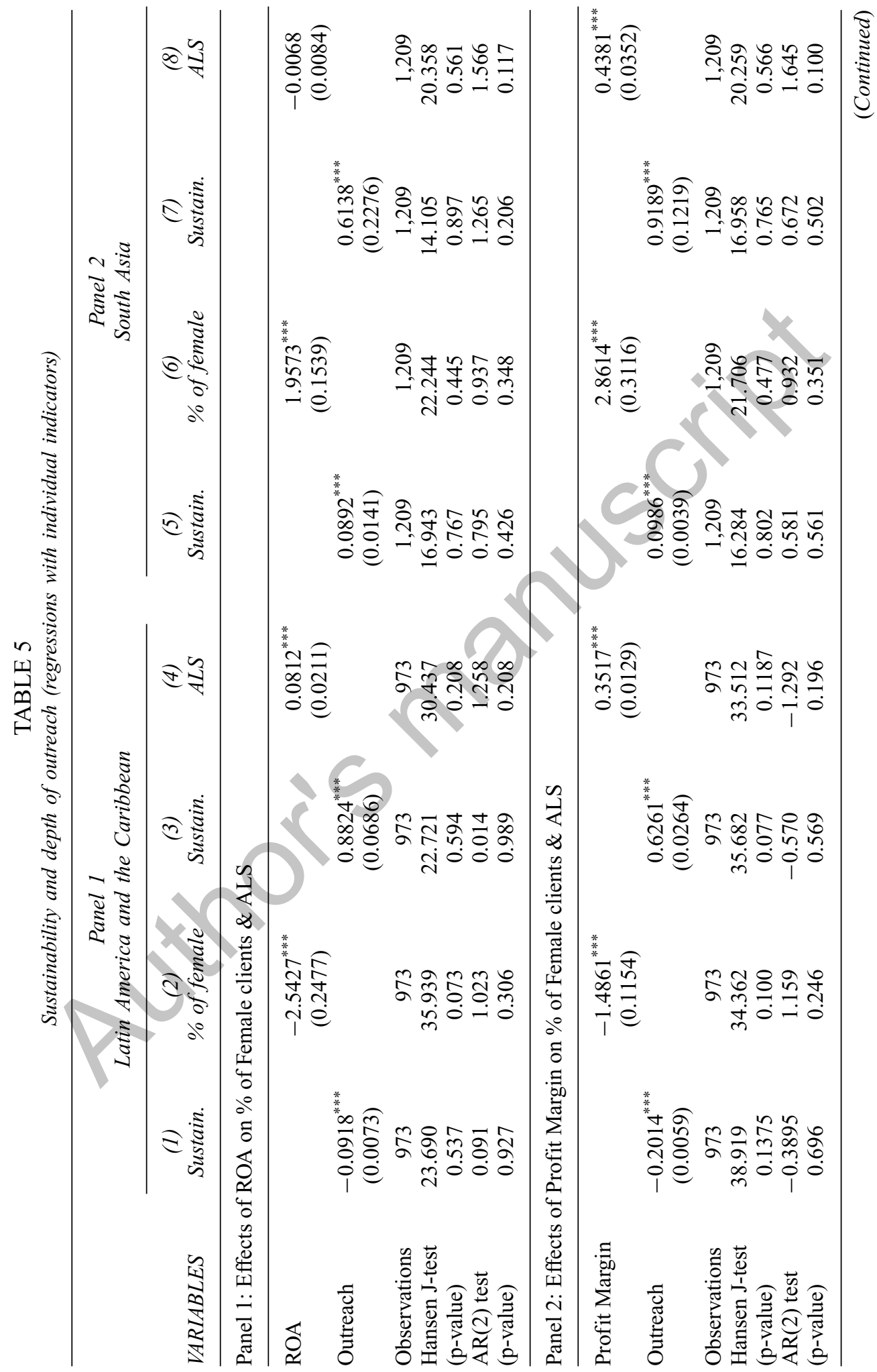


Microfinance Sustainability and Outreach

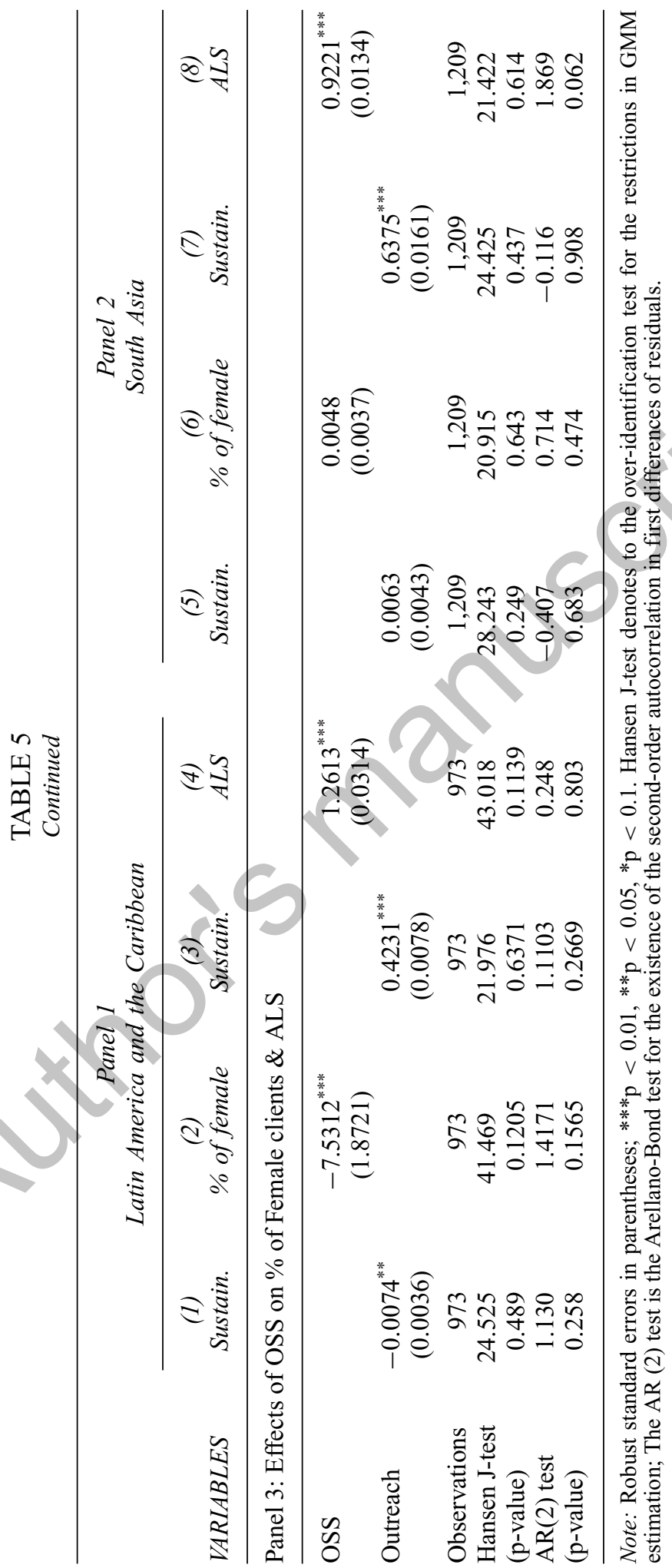


ALS) is associated with a 0.88 percent increase in ROA in LAC. Similarly, a 1 percent increase in financial performance (ROA) is associated with a 0.08 percent increase in average loan size (i.e., a decline in outreach depth). With regards to the relationship between profit margin and average loan size, results from Panel 2 indicate that for both regions, an increase in ALS is associated with an increase in the profit margin of MFIs while increases in profit margin are associated with higher ALS. This confirms a trade-off between sustainability (measured by profit margin) and depth of outreach (measured by ALS).

Furthermore, we note that the effect of a unit increase in profit margin on ALS is stronger for MFIs in SA than those in LAC. Results also indicate that a 1 percent increase ALS is associated with a 0.63 percent increase in profit margin in the case of $\mathrm{LAC}$, while for SA, a 1 percent increase in ALS is associated with a 0.92 percent increase in profit margin. Thus, we find that MFIs that give bigger loans in SA report higher profit margins than MFIs in LAC. Similar results are observed in Panel 3 as well, where results are presented for the association between OSS and ALS. We observe that a 1 percent increase in ALS is associated with a 0.63 percent and 0.42 percent increase in OSS in SA and LAC, respectively. This suggests that giving out bigger loans is more rewarding in terms of OSS for MFIs in SA than MFIs in LAC. In addition, results indicate that depth of outreach is compromised more severely in LAC than in SA when MFIs attempt to improve their OSS. In essence, in an attempt to improve OSS, MFIs in LAC tend to give out larger loans compared to MFIs in SA.

IV.1.3 Sustainability and breadth of outreach indicators. Table 6 presents results for the association between sustainability and breadth of outreach using individual indicators rather than indices. Trends in the results suggest that overall, there is no trade-off between sustainability and breath of outreach in both regions. For LAC, across all panels, we note that indicators of outreach breath are positively associated with sustainability indicators. Specifically, an increase in each measure of outreach breadth, leads to an increase in sustainability indicators. This finding is also true for SA but it is not robust across all measures of sustainability.

On the other hand, the effects of sustainability measures on outreach measures are negative, where significant. For instance, results for SA indicate that a 1 percent increase in MFI profit margin leads to a 0.36 percent and $0.48 \%$ decline in the number of borrowers and offices, respectively. Similarly, a 1 percent increase in OSS leads to a 1.92 percent decrease in the total number of borrowers, and a 0.89 percent decline in number of offices. In the case of LAC, we find that ROA, profit margin and OSS have negative effects on total number of borrowers. OSS also has a negative effect on the total number of offices. Thus, as MFIs in LAC attempt to increase profitability in terms of their ROA, profit margin and OSS, it negatively affects the number of borrowers.

Overall, results indicate that there is no trade-off between sustainability and breadth of outreach in both LAC and SA. However, while focussing on the expansion of outreach breadth, MFIs in LAC have the advantage of performing better financially compared to MFIs in SA.

\section{IV.2 The effects of Other Regressors}

Turning to the effects of the other regressors on both sustainability and outreach, we observe that from Table 2, LLR has a negative effect on sustainability. Thus, as the levels of loan default increase, MFI sustainability declines. However, GMMM results show a statistically insignificant effect of LLR on outreach (Tables 2 and 3). For the relationship between cost per borrower and our sustainability measures, we observe that cost per borrower is negatively associated with both sustainability and depth of outreach. However, this relationship appears to be quite weak 
Microfinance Sustainability and Outreach

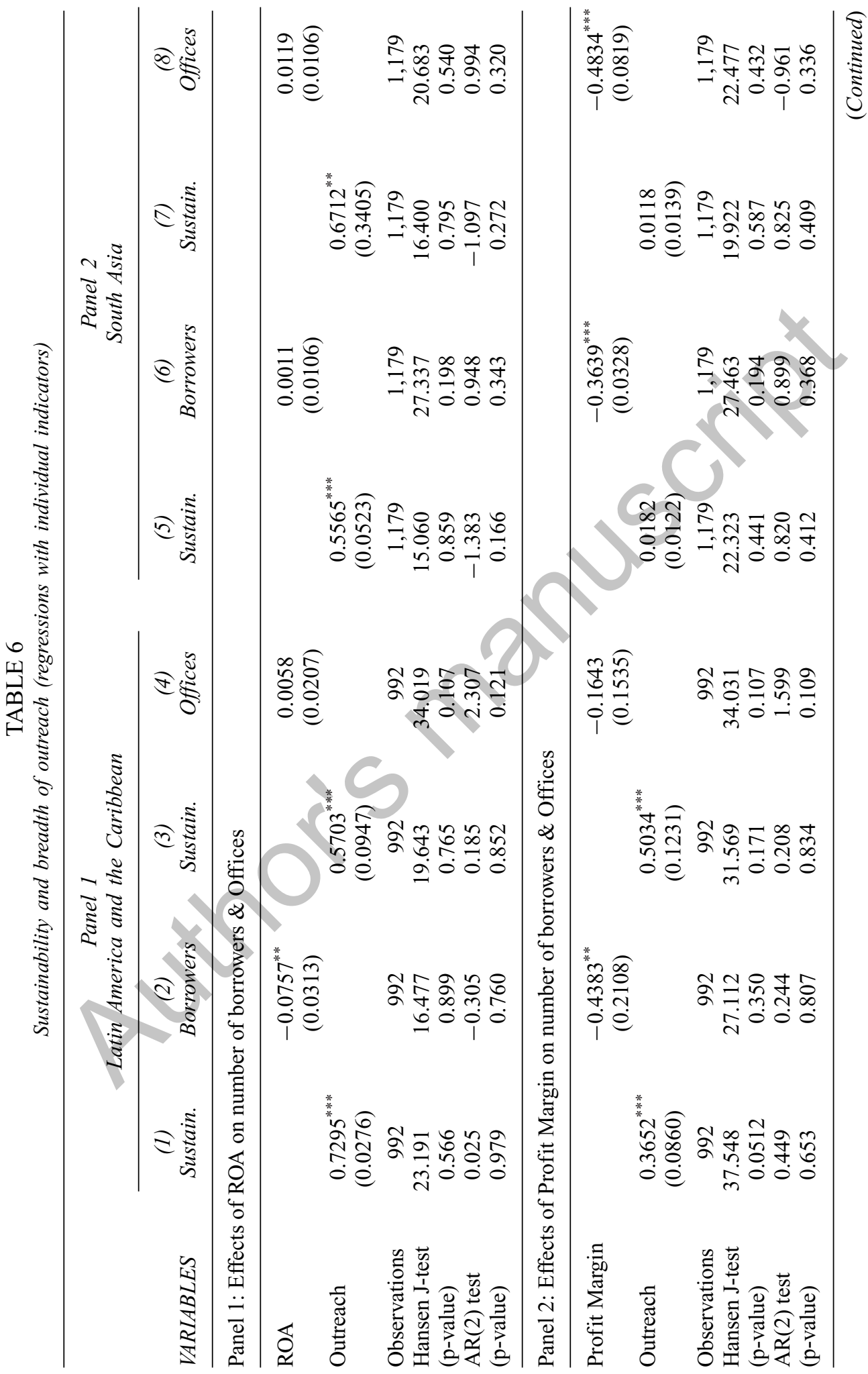




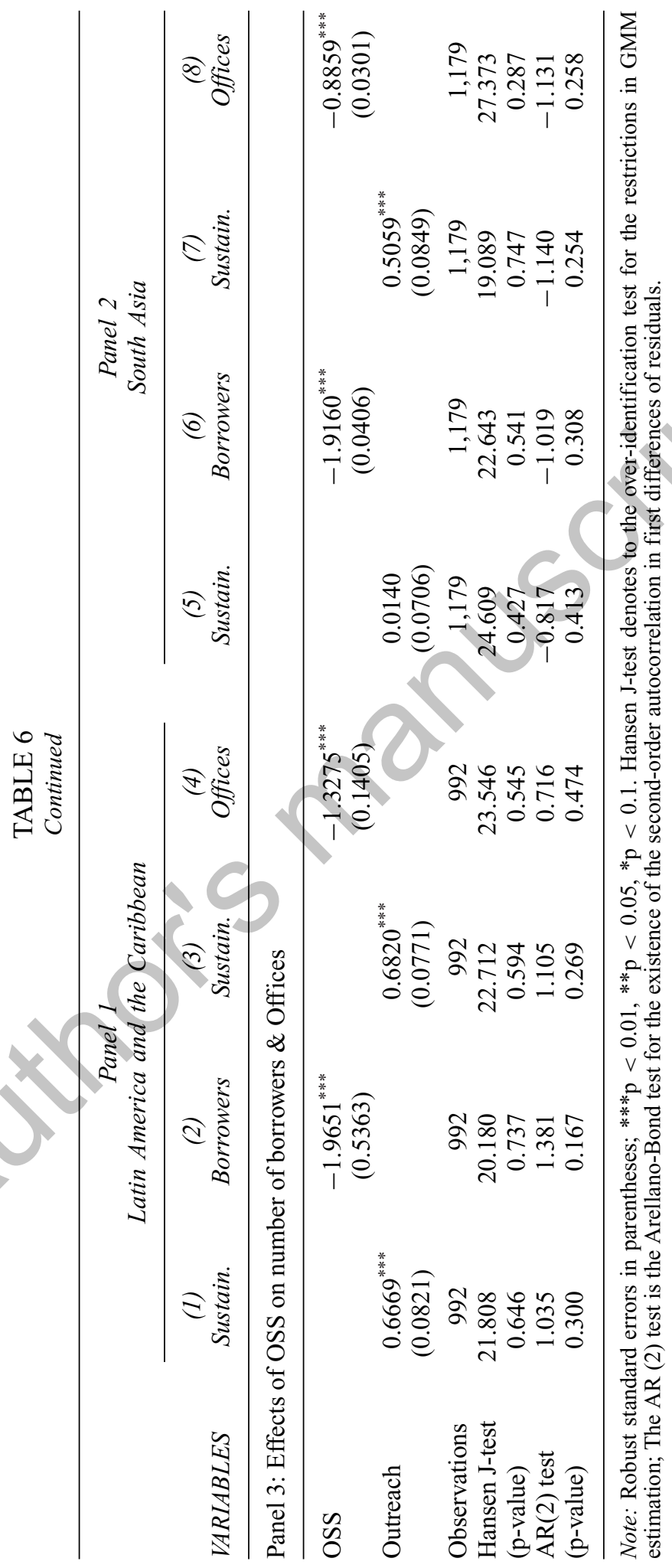


with a coefficient of 0.0001 . Cost per borrower gives an indication of how expensive loans are. It is calculated as the ratio of MFI operating expense to the total number of borrowers. Thus, a higher cost per borrower ratio suggests that loans are expensive and this can deter borrowers. As a result, when expensive loans drive clients away, it potentially affects their profitability and consequently sustainability.

The above result leads us to conclude that expensive loans are associated with lower levels of outreach depth. This suggests that expensive loans (determined by higher cost per borrower) are associated with an increase in ALS, and therefore a decline in outreach depth. Given that bigger loans are associated with relatively rich clients, evidence suggests that there is a re-orientation from the poorest clients to the less poor when operating expenses increase. Furthermore, based on results from Table 3, breadth of outreach is also compromised when the cost per borrower increases.

Deposit account serves as a proxy that captures the level of savings among microfinance clients and we expect that increase in the number of savings account would help MFIs expand outreach, especially outreach breadth. Examining GMM results from Tables 2 and 3, we observe that increase in deposit accounts leads to an increase in sustainability and outreach breath. However, we find no significant effect on depth of outreach. Thus, consistent with economic theory, an increase in deposit accounts (savings) gives MFIs the leverage to perform well financially.

For the association between MFI age and our outreach measures, GMM results are statistically insignificant for the new MFI dummy. However, across other specifications, the dummy for mature MFIs is mainly positive and significant while the dummy for new MFIs is negative in sustainability regressions. Hence we conclude that older MFIs perform better than younger MFIs in terms of sustainability.

For the relationship between profit status and performance, results from Tables 2 and 3 indicate that compared to for-profit MFIs, not-for-profit MFIs perform poorly in terms of sustainability. Furthermore, while there is no significant effect of profit status on depth of outreach, results show that not-for-profit MFIs perform poorly in terms of outreach breadth compared to for-profit MFIs.

Lastly, for loan portfolio, results show that an increase in the gross loan portfolio leads to a decrease in outreach depth. On the other hand, as MFIs' gross loan portfolio increases, the breadth of outreach also increases. Overall, these results suggest that, higher loan portfolios for MFIs could lead to mission drift. This is evident given that our results indicate a positive association between outreach breadth and gross loan portfolio but a negative association between depth of outreach and gross loan portfolio.

\section{CONCLUSIONS}

The paper has dealt with the issue of possible trade-off (or not) between financial sustainability and outreach performance by MFIs in two known major microfinance regions in the world, namely South Asia (SA) and Latin America and the Caribbean (LAC). Even though microfinance emerged about the same time in both regions, the industry in each has presented differing characteristics over time. One of the most enduring and prominent dissimilarities is the fact that, due to the prevailing economic conditions in the regions, LAC adopted an early approach towards the notion of profitability when running microfinance institutions, while in SA, MFIs were primarily concerned with alleviating poverty and aiming at targeting the poorest households.

Our research findings indicate that trade-offs exist between depth of outreach and financial sustainability in both regions. Interestingly, our evidence seems to suggest that there are limits to 
the particular strategic focus that each geographical area has specialized in. That is to say, where the emphasis has been primarily on achieving financial sustainability (as in LAC), persistence in maintaining this focus leads to a greater loss in depth of outreach compared to SA. Similarly, a continuous emphasis on depth of outreach compromises financial sustainability to a greater extent in SA than in LAC. This suggests that a more balanced strategy is recommended in both regions whereby both depth of outreach and financial sustainability are pursued as long as they complement each other. To this end, further research is needed in order to answer key questions such as: where do these strategic limits lie? Is it possible to avoid over-stepping these limits? What policies need to be implemented so as to identify frontiers and ways to improve strategies?

Further evidence of trade-off demonstrates a connection to the particularities of each region. For instance, our findings show that MFIs in SA have to issue larger loan amounts than those in LAC for one unit increase in profit margin and one unit increase in OSS. This may be explained by the fact that, generally speaking, in SA disbursed loan amounts start at a much lower base than those in LAC. This relates to the particular focus on poverty alleviation in SA. For this reason, MFIs in SA need a much larger increase in loan amounts to achieve a 1 percent increase in profit margin or OSS.

However, in terms of outreach to female clients, our research findings provide mixed results. While there is no trade-off in SA between financial sustainability and reaching female clients, LAC extends less finance to women when focussing on financial sustainability. The reason for the latter finding might be because provision for female clients demands the extension of other services such as health protection and group formation, while these services are well established in SA, particularly in India, via self-help groups.

In conclusion, our study has shown that trade-offs between the two major microfinance goals still exist in some important aspects and that these relate closely to the particular strategies that each of the regions has chosen to emphasize. Thus, it would be in the best interest of microfinance practitioners and policymakers to assess the benefits and costs of maintaining such strategies and those of adopting new mechanisms, which can lead to greater complementarity of objectives.

\section{REFERENCES}

Arellano, M. and Bond, S. (1991). 'Some tests of specification for panel data: Monte Carlo evidence and an application to employment equations', The Review of Economic Studies, 58, pp. 277-97.

Bhatt, N. and Shui-Yan, T. (2001). 'Making microcredit work in the United States: Social, financial, and administrative dimensions', Economic Development Quarterly, 15, p. 229.

Blundell, R. and Bond, S. (1998). 'Initial conditions and moment restrictions in dynamic panel data models', Journal of Econometrics, 87, pp. 115-43.

Conning, J. (1999). 'Outreach, sustainability and leverage in monitored and peer-monitored lending', Journal of Development Economics, 60, pp. 51-77.

Cull, R., Demirguc-Kunt, A. and Morduch, J. (2007). 'Financial performance and outreach: A global analysis of leading microbanks', Economic Journal, 117, pp. F107-133.

Fernando, N. (2004). 'Micro success story, transformation of nongovernmental organizations into regulated financial institutions', in Manila Asian Development Bank.

Hartarska, V. and Nadolnyak, D. (2007). 'Do regulated microfinance institutions achieve better sustainability and outreach? Cross-country evidence', Applied Economics, 39, pp. 1207-22.

Helms, B. (2006). Access for All: Building Inclusive Financial Systems: Washington, D.C.: World Bank. 
Hishigsuren, G. (2007). 'Evaluating mission drift in microfinance lessons for programs with social mission', Evaluation Review, 31, pp. 203-60.

Hulme, D. and Mosley, P. (1996). Finance Against Poverty. London: Routledge.

Inoue, T. and Hamori, S. (2013). 'Financial permeation as a role of microfinance: has microfinance actually been a viable financial intermediary for helping the poor?', Applied Financial Economics, 23, pp. 1567-78. doi: 10.1080/09603107.2013.839859

Kai, H. (2009). 'Competition and wide outreach of microfinance institutions', Economics Bulletin, 29, pp. 2628-39.

Makame, A. H. (2008). Treatise on the outreach-sustainability trade-off in microfinance operations. Unpublished Ph.D., University of Birmingham (UK), Ann Arbor.

Marr, A. and Awaworyi, S. (2012). 'Microfinance social performance: a global empirical study', Applied Econometrics and International Development, 12, pp. 51-68.

Mersland, R. and Strøm, Ø. (2010). 'Microfinance mission drift?', World Development, 38, pp. 28-36.

Navajas, S., Schreiner, M., Meyer, R. L., Gonzalez-vega, C. and Rodriguez-meza, J. (2000). 'Microcredit and the poorest of the poor: Theory and evidence from Bolivia', World Development, 28, pp. 333-46.

Olivares-Polanco, F. (2005). 'Commercializing microfinance and deepening outreach? Empirical evidence from Latin America', Journal of Microfinance, 7, pp. 47-69.

Quayes, S. (2012). 'Depth of outreach and financial sustainability of microfinance institutions', Applied Economics, 44, 3421-33.

Quayes, S. (2015). 'Outreach and performance of microfinance institutions: A panel analysis', Applied Economics, 47, pp. 1909-25. doi: 10.1080/00036846.2014.1002891

Quayes, S. and Khalily, B. (2014). 'Efficiency of microfinance institutions in Bangladesh', Economics Bulletin, 34, pp. 1512-21.

Rhyne, E. (1998). 'The Yin and Yang of microfinance: reaching the poor and sustainability', MicroBanking Bulletin, 2, pp. 6-9.

Roodman, D. (2006). How to do xtabond2: An introduction to difference and system GMM in Stata. Center for Global Development working paper (103).

Rutherford, S. (2003). 'Money talks', Journal of Microfinance, 5, pp. 43-75.

Schreiner, M. (2002). 'Aspects of outreach: a framework for discussion of the social benefits of microfinance', Journal of International Development, 14, pp. 591-603.

Weiss, J. and Montgomery, H. (2005). 'Great expectations: microfinance and poverty reduction in Asia and Latin America', Oxford Development Studies, 33, pp. 391-416.

Woller, G. (2007). 'Trade-offs between social and financial performance', in ESR Review (9, pp. 14-9): ESR Review.

World Bank (2007). Microfinance in South Asia: Toward Financial Inclusion for the Poor Washington, DC: World Bank.

Zeller, M., Wollni, M. and Abu Shaban, A. (2003). 'Evaluating the poverty outreach of development programs: results from case studies in Indonesia and Mexico', Quarterly Journal of International Agriculture, 42, pp. 371-83. 